\title{
WAYS OF ENHANCEMENT OF OPERATIONAL PLANNING PROCESS IN THE SERBIAN DEFENCE ORGANIZATION
}

\author{
Nikola Pekić \\ Ministry of Defence of Republic of Serbia, \\ Defence Policy Sector, Strategic Planning Department
}

\begin{abstract}
The purpose of this paper is to outline the policies, processes, procedures, and responsibilities governing the preparation, approval, promulgation, activation, implementation, review, and cancellation of operational planning documents necessary to execute the tasks allocated to all levels of command. These procedures and guidelines apply to two categories of operational planning - deliberate (advance) and crisis response planning - that cover and prepare the Serbian defence organization to meet future or developing crisis in the full spectrum of operations from crisis management to major aggression.

Consideration must be given to expanding and including the internal Serbian MOD civil-military interface for use in operational planning. In line with contemporary defence policy and trends, military planners should integrate Civil Emergency Planning (CEP) planners, as well as liaison with other defence system relevant agencies and organizations, into the appropriate steps of the operations planning process.
\end{abstract}

Key words: Operational Planning, Operational Planning Process (OPP), Planning Categories, Planning Tools

\section{General background}

Dlanning is performed at every echelon of command, and it is conducted across a range of military operations. Military planning includes two broad categories of planning:

1. force planning and

2. joint operational planning.

Force planning is associated with the creation and maintenance of military force structure and capabilities. The General Staff of the Serbian Armed Forces should conduct force planning for the long-term development of the Serbian Armed Forces. The services should conduct force planning for recruitment, organizing, training, equipping, and provision of forces for assignment to the Operational Commander.

*nikola.pekic@mod.gov.rs 
The focus of this paper is operational planning, which is directed toward the employment of military forces within the context of a military strategy to attain specified objectives through the conduct of possible future contingencies. Operational planning includes the preparation of plans and orders by all levels of command as well as those planning activities that support the development of these operation plans or orders. These activities incorporate the functions of the General Staff of the Serbian Armed Forces, Services and four Brigade Commands.

The establishment of a sound training program for commanders and their planning staffs on how operational art can be used to create effective operational designs will ensure the sound basis for future operational planning and will assist their determination of when, where and for what purposes forces will be employed.

\section{Levels of operational planning}

Operational planning is a sequential process performed simultaneously at the strategic, operational, and tactical levels.

\section{Strategic-military level}

At the strategic level, joint operational planning involves the development of strategic military objectives and tasks in support of the National Security Strategy of the Republic of Serbia and the development of the force and materiel requirements necessary to accomplish those tasks. The National Military Strategy (should be developed, so far there is only the Defence Strategy of the Republic of Serbia), developed with extensive military advice from the $\mathrm{CHOD}$, translates national security policy into national strategic military objectives. These military objectives facilitate national strategic planning. Some of this strategic planning may be done in concert with allies and/or coalition partners.

Basically, irrespective of the circumstances, policy must be identified first. The MOD, or civil-military relations, plays a key role in shaping policy at the political/military strategic level. Once policy is established, the following key questions need to be answered to formulate the strategy: what and why; with whom; scale and risk; for how long; where and when; concurrent with; against whom; and, at what cost?

In the light of civil-military relations and from the perspective that Serbian Defence Organization is policy driven, the Serbian MOD, as the interface between the civil and military levels of Serbian Defence Organization, should provide military advice upward and convert policy and political guidance into military direction downwards. It is at this level that strategic political objectives are converted into supporting strategic military objectives, with a desired military end-state. In my point of view and in the Serbian Defence Organization's context, these issues should be covered in the appropriate Minister of Defence's Initiating Directive. The Ministry of Defence then becomes the head of mission or strategic commander's responsibility, with the assistance of all the major contributing agencies/players to develop the political/military plan for the operation. Military authorities should prepare Contingency Plans (CONPLANs) and Concepts of Operations (CONOPS) to cover possible changes in the political and military strategic situation. Military activity at the strategic and operational level will clearly be influenced, and ultimately directed, by political considerations including national 
discrete command authorities. The need to consider the political dimension applies equally across the range of operations. With this in mind, a commander at the operational level may well require political advice, which could be provided either by a nominated adviser on the spot or by strategic guidance provided through the chain of command.

\section{Operational level}

Operational planning at the operational level links the tactical employment of forces to strategic objectives. The focus at this level is on the operational art - the employment of military forces to attain strategic and/or operational objectives through the design, organization, integration, and conduct of strategies, campaigns, major operations, and battles. Operational art determines when, where, and for what purpose major forces will be employed and should influence enemy force disposition. It governs the deployment of those forces, their commitment to, or withdrawal from, battle and the arrangement of battles and major operations to achieve operational and strategic objectives.

In addition, according to NATO Joint Doctrine, the operational level is 'the level of operations at which campaigns and major operations are planned, conducted, and sustained to accomplish strategic objectives within theatres or areas of operations'. The operational level provides the vital link between strategic objectives and the tactical employment of forces. Without this link, it is unlikely that tactical actions will lead to the achievement of strategic endstate. So appropriate activities must be linked by the operational level to the aims of the overall strategy, but the strategy should also be linked through the operational level to what is tactically realistic. Of prime importance is for the operational level Commander to understand clearly how his activities mesh with other strategic lines of operation.

The employment of the whole force through the conception, planning, and execution of operations is addressed at the operational level. Operational level activity must contribute directly towards achieving previously defined military strategic objectives, which are themselves drawn from the overarching political aims of the operation. Tactical activity cannot take place purposefully outside this context.

\section{Tactical level}

At the tactical level of planning, tactics is the employment of units in combat. It includes the ordered arrangement and manoeuvre of units in relation to each other and to the enemy in order to use their full potential. Tactics are employed to fight and win engagements and battles.

\section{Process of operational planning}

The Operational Planning Process (OPP) is a co-ordinated staff process to determine the best method of accomplishing assigned tasks or planning for possible future tasks or mission requirements. Because planning will usually be inhibited by inadequate information, insufficient time and limited resources, the OPP is designed to optimize logical, analytical steps of decision making under conditions of uncertainty and ambiguity. The Operational planning is carried out within a strategic framework and seeks to translate strategic guidance and direction into a 
scheduled series of integrated military actions, carried out by joint forces to achieve strategic objectives efficiently and with acceptable risks. It requires the ability to envisage the employment of forces and their effects in time and space and to anticipate possible outcomes. Operational art is applied to determine when, where and for what purpose forces will conduct operations and to create an operational design as the basis for further planning. The OPP is applicable to any Strategic, Operational or Tactical $\mathrm{HQ}$ conducting planning for any theatre, for any kind of plans and with any size of force. The process is intended to enable commanders to integrate the efforts of various separate forces and commanders into the planning process so that an effective overall co-ordinated planning effort can result. Whereas the OPP is applicable for both Advance and Crisis Response Planning, Advance Planning is usually conducted with more time available to complete the process. Crisis Response Planning, due to time constraints, normally demands an accelerated use of the process.

The goals of this Operational Planning Process:

- Standardize and formalize the planning process and make it compatible with NATO (as a PfP country).

- Provide for strategic/political direction and control throughout the planning process.

- Provide a logical process for analysing higher-level direction and guidance and developing viable operational plans to achieve a desired military end-state.

- Enhance the commanders' ability to direct and guide the development of the plan.

- Provide a means to manage the time required for planning by creating a family of standing plans to draw upon in Crisis Response planning.

- Maximize logical and creative thinking by staffs to enhance the ability of commanders to make better decisions under conditions of uncertainty and ambiguity when time and information may be insufficient.

- Enable commanders to co-ordinate and integrate the efforts of different forces and commands during operational planning.

- Evaluate the products of the planning process.

\section{The realm of Operational Planning}

The realm of operational planning addresses the following main areas:

Conduct of operation to achieve strategic, operational, and tactical objectives.

- Force capabilities required to conduct the operation.

- Deployment of forces into the area of operations.

- Logistical sustainment.

- Control and use of operational information.

- Arrangements for command and control.

- The risks associated with planned operations.

\section{Principles of Operational Planning}

Operational planning may be carried out at different levels under varying circumstances and produce different products. In any case, the following are fundamental to any operational planning effort:

- Establish and focus on achieving strategic objectives and the desired end-state.

- Incorporate the higher commander's intent. 
- Account for the operational environment, including civil aspects.

- Appreciate the capabilities, limitations, and likely intentions of opposing forces.

- Orient on opposing Centres of Gravity (COGs).

- Ensure protection of own COGs.

- Achieve unity of effort with air, land, and sea forces in conjunction with the United Nations and other international and non-governmental organizations as required.

- Describe the sequence of related joint operations from initial entry through termination throughout the area of operations.

- Clearly define criteria for measuring success.

- Provide direction, operational objectives, and major tasks to subordinates as the basis for their planning.

- Ensure the provision of adequate sustainment.

- Establish the task organization of forces and command arrangements.

In the sense of the unity of purpose and effort, Operational planning requires a high degree of centralized activity in order to ensure that all planning agents remain focused on the strategic purpose. Activities of different planning staffs must be unified by a common appreciation of the strategic direction and the operational environment as well as a thorough understanding of the commander's intent. In addition, the use of common doctrine and procedures are required to ensure unity of effort.

Relating to direction and requirements, Operational planning involves concurrent activity at different levels of command in iterative cycles as planning matures from a basic idea, to a concept and finally to a mature plan. Guidance and direction are transmitted from higher to lower levels of command while requirements for resources and requests for information are transmitted from lower to higher for approval. Operational planning at any level should take account of guidance two levels above and requirements two levels below.

Concerning reverse engineering, Operational planning seeks to describe the sequence of actions, which have the greatest likelihood of setting the military conditions that are required to achieve a strategic goal. Therefore, it is usually necessary to describe those conditions and work backwards to the initial entry or build-up of forces in the area of operations to identify the activities most likely required to establish those conditions over time.

\section{Structure of Operational Planning Process}

An Operational Planning Process (OPP) must describe a logical sequence of cognitive processes and associated procedures that will be undertaken by commanders and staffs to analyse a situation, deduce mission requirements, and determine the best method for accomplishing assigned tasks and achieve the desired military end-state. The OPP must include, inter alia, the identification of military force capabilities and the task organization required to carry out the operation. A sound understanding of the operational planning principles outlined above is required if the OPP is to be applied effectively.

The OPP is used to produce plans to reach the desired end-state and to achieve the commander's mission requirements. The process is essentially the responsibility of the commander and his planning team and describes a deductive reasoning process for moving from general details to specific options. The process as outlined has five planning stages: initiation, orientation, concept development, plan development, and plan review. 


\section{Planning Categories}

In order for the Serbian Armed Forces to be able to undertake the full range of its roles and missions, two operations planning categories could be used: Deliberate (Advance) Planning and Crisis Response Planning.

\section{Deliberate (Advance) Planning}

Deliberate planning consists of initiating and developing scenario-based plans in anticipation of a future event or circumstance - security risks - that the Republic of Serbia might face. Furthermore, the deliberate planning is conducted with a view to preparing the Serbian Armed Forces to deal with possible future security challenges in the best possible way and respond in time. It entails a comprehensive iterative co-ordination and approval process, which has been outlined above. The final outcome of Deliberate (Advanced) Planning will be one of three types of plans: a CONPLAN, FP or SDP.

\section{Contingency Plans (CONPLANs)}

CONPLANs are prepared for potential future events or circumstances and are based on known or assumed planning factors. CONPLANs are to be based on planning guidance, in the form of an Initiating Directive, and may be developed at any command level. Contingency Plans are the normal final outcome of Contingency Planning. These plans, produced in as much detail as possible, enhance the approved CONOPS and serve as a basis for subsequent operational planning. CONPLANs are developed in co-ordination and consultation with relevant commanders and civil authorities, to include international security organizations or friendly nations if applicable. Also, a CONPLAN should address the potential future force and capability requirements necessary for the conduct of the mission, out to an agreed and understood planning horizon. This way, CONPLANs can significantly accelerate the defence planning process.

\section{Functional plans (FPs)}

Functional plans involve the conduct of military operations in a peacetime or permissive environment. These plans are traditionally developed for specific functions or discrete tasks (e.g., nuclear accident or evacuation, logistics, communications, or continuity of operations) but may also be developed to address functional peacetime operations such as disaster relief, humanitarian assistance or peacekeeping operations. Functional plans are written using the procedures and formats specified for a CONPLAN.

\section{Standing Defence Plans (SDPs)}

An SDP should be designed to support the Serbian Armed Forces response to short/no-notice potential risks when the Forces are in a peacetime posture. The requirement for an SDP will be included in a commander's Terms of Reference (TOR). Approval of the TOR constitutes the necessary authority for the Commander to initiate planning. Development of SDPs requires co-ordination with concerned commanders and civil authorities, to include friendly nations if applicable. A complete SDP will be a fully developed plan that can be readily executed, with forces assigned and execution authority delegated to the appropriate level of command. 


\section{Crisis Response Planning}

Crisis Response Planning consists of initiating and developing plans in response to a current or developing crisis that has not escalated to the point or in the direction anticipated by any SDP. It requires expeditious preparation, co-ordination, and approval of operational plans. Crisis Response Planning may use an existing CONPLAN, if available, to guide the development of an Operation Plan (OPLAN). An OPLAN is the end product of crisis response planning.

Operation Plans (OPLANs). OPLANs are plans developed in response to a current or developing crisis. They are based on an Initiating Directive, and may be developed at any command level. OPLANs are produced in sufficient detail for execution, may enhance a CONOPS previously submitted for approval to the Initiating Authority, and are developed in co-ordination and consultation, at the appropriate level, with relevant commanders and civil authorities, to include friendly nations if applicable. Finalized strategic level OPLANs include all appropriate supporting annexes as well as force requirements. OPLANs are approved by the Initiating Authority. All in all, if a crisis was foreseen, the OPLAN might be developed from an appropriate CONPLAN although it is still necessary that it follows the OPLAN development process in order to test and validate earlier planning assumptions; if the crisis was not foreseen, the OPLAN must be developed in response to the prevailing circumstances. An OPLAN is a detailed and comprehensive plan capable of execution, which has forces assigned for which preparations will be complete.

\section{Planning tools}

The military commanders implement national guidance through a series of planning tools, to include the following.

\section{Political-Military Estimate (PME)}

In response to an actual or developing crisis, national authorities may undertake a politicalmilitary estimate (PME), taking account of both strategic political direction and military considerations, to identify a range of potential political and military response options for dealing with a crisis. This would normally commence with consideration of possible crisis management actions, which could include military activities, as appropriate. The identified options will then be scrutinized by the Ministry of Defence to provide direction to the CHOD and assist his operational planning staff in the further development or refinement of potential military response options. The PME process, by its nature, will assist the political decision-making process. Once the Minister has agreed on a way forward, the CHOD may be directed to undertake further detailed operational planning, which may lead to the development of an OPLAN.

\section{Military Estimate}

The military estimate process involves mission analysis, which is followed by the identification of the various courses of action (COA) available to the military commander for the accomplishment of the mission. 


\section{Military Response Options}

In crisis management, military response options (MROs) are courses of action, which may be taken in a coordinated and timely manner alongside political, diplomatic and/or economic actions. An MRO can be developed for a military response in the early stages of a crisis, when the threat may still be ambiguous and where national territory is not necessarily threatened. The MRO may be designed to covertly increase the preparedness of the forces, or to send clear signals of national resolve to a potential adversary. The MRO may be applicable as a crisis management tool during national deliberations leading to the activation of a SDP or initiation of an Operational Plan.

Examples of potential MROs include:

Options with preventive political effect. These could include making statements, convening meetings, imposing restrictions on military contacts and assistance.

Options to counter risks of a wider nature. These could include intelligence sharing, collective assessments, consultation, coordination of support, cooperation of individual nations, and assistance as well as other military activities.

Options drawn from CSBMs and Arms Control Provisions. These could be used to coordinate and concentrate the Treaty Verification efforts in an area, to restrict intelligence gathering by a potential enemy through the exploitation of Verification procedures.

Surveillance - Options to Monitor Developments in an Area of Potential Crisis. These could provide for the use of military surveillance assets or information sharing arrangements with friends and allies to assist in the compilation and maintenance of a comprehensive picture of the evolving security environment.

Readiness - Options for Raising Readiness in Response to a Developing Crisis. These could raise the readiness of commands and forces and provide for the use of exercises as a political signal. These options should be considered together with the military responses listed under the Deterrence options.

Deterrence - Options for Increasing Deterrence and Demonstrating National Resolve. These could complement those designed to raise readiness and could in some cases contribute to the containment of a crisis. These options should be considered together with the Readiness and Containment options.

Containment - Options for Containing a Crisis by Means Short of the Application of Force. These could provide a range of non-violent actions including the enforcement of sanctions on trade and or goods as directed by the international body imposing the sanctions.

De-escalation - Options to De-escalate a Crisis. These should be dictated by the national political aim and the nature of the crisis.

\section{Functional Planning Guides (FPGs)}

To support planning for operations in conjunction with NATO forces, it is important that planners consider the use of available NATO FPGs. FPGs provide planning guidance in specific functional areas and detail unique planning considerations within a specific functional area that are not covered elsewhere. 


\section{Regional Planning Guides (RPGs)}

To support planning for operations in conjunction with NATO forces, it is important that planners consider use of available NATO RPGs that detail unique planning considerations within the Area of Responsibility (AOR) of each NATO Regional Command.

\section{Specific Planning Guides (SPGs)}

NATO Commanders' SPGs provide further essential planning guidance unique to their command. Like FPGs and RPGs, they are designed to supplement and not repeat available planning information. As above, these documents can support the Serbian Armed Forces' planning for operations in conjunction with NATO forces.

\section{Initiating Directive}

The Initiating Directive is an instrument to start and guide operational planning but it is not the authority to execute. It provides the situation, political and/or military objectives, tasks and the desired political and military end states. They may take the form of the Commander's Planning Guidance or a Warning Order.

\section{Concept of Operations (CONOPS)}

The completion of a CONOPS document is a preliminary step in the development of an operational plan. The CONOPS expresses the military commander's intentions on the use of forces, time, and space to achieve his mission, objectives, and end state. It includes how the capabilities of the available resources are to be synchronized towards this goal. The CONOPS is the final output of the Concept Development Stage of the OPP and is submitted for approval, in document form, to the appropriate Initiating Authority. CONOPS approval is not a pre-requisite for further plan development, but approval is a pre-requisite for full plan development. A CONOPS document usually consists of a situation overview, mission statement, commander's intent, outline concept for execution, force capability requirements, outline logistic support concept, key command and control arrangements, and other resource requirements. The CONOPS does not include any of the detailed annexes found within a fully developed plan or any supporting plans.

\section{Supporting Plans (SUPLANs)}

SUPLANs provide detailed amplification for particular functional planning areas and must be directly linked to a specified CONPLAN, SDP, or OPLAN. A SUPLAN can be a stand-alone document or can be incorporated as an annex within the supported main plan. The agency providing the support develops the SUPLAN, which must be endorsed by the supported commander and approved by the next higher commander. The full range of SUPLANs includes but is not limited to the mobilization, deployment, sustainment, and redeployment of forces. Specific examples are: Mobilization Planning, De- 
ployment/Redeployment Planning, Sustainment Planning, Force Reception and Onward Movement Planning, and Host Nation Support Planning.

Mobilization Planning. Primarily the responsibility of the $\mathrm{HQ}$ of the Serbian Armed Forces, mobilization planning is directed toward assembling and organizing national resources to support the achievement of stated national objectives. Mobilization planning includes bringing all or part of the Serbian Armed Forces to the necessary state of readiness to meet the requirements of the specific contingency. Mobilization planning may include planning for the activation of all or part of the Reserve components, as well as assembling and organizing personnel, supplies, and materiel. A mobilization SUPLAN will support developed CONPLANs, SDPs, OPLANs and other SUPLANs as appropriate.

Deployment/Redeployment Planning. Deployment/redeployment planning is the responsibility of the Operational Commander in close coordination with the $\mathrm{HQ}$ of the Serbian Armed Forces. Deployment planning is planning to move forces and their sustainment resources from their original locations to a specific operational area to conduct operations outlined in a given plan. Redeployment planning is planning to move forces and their sustainment resources to a different operational location or to home station. A deployment/redeployment SUPLAN will support developed CONPLANs, SDPs, OPLANs, and other SUPLANs as appropriate.

Sustainment Planning. Sustainment planning is directed toward providing and maintaining levels of personnel, materiel, and consumables required to sustain the planned levels of military activity for the estimated duration and at the desired level of intensity. The sustainment planning for out-of-country deployments could incorporate bi- or multilateral agreements. A sustainment SUPLAN could have a sub-plan for HNS. Sustainment planning is the responsibility of the force commanders in conjunction with appropriate authorities. A sustainment SUPLAN will support developed CONPLANs, SDPs, OPLANs, and other SUPLANs as appropriate.

Force Reception and Onward Movement Planning. This type of planning focuses on the reception and integration of friendly forces into the Serbian Armed Forces defence operations. This planning must ensure that the personnel, materiel, and C2 elements necessary to support such operations are readily available. This planning is responsibility of the Operational Commander with the support of $\mathrm{HQ}$ of the Serbian Armed Forces and the MOD. This type of SUPLAN will support developed CONPLANs, SDPs, OPLANs and other SUPLANs as appropriate.

Host Nation Support Planning. This type of planning should cover the HNS rendered to friendly forces deploying into the Republic of Serbia, as well as HNS requirements for the Serbian Armed Forces components deploying outside the Republic of Serbia. The HQ of the Serbian Armed Forces and MOD support and conduct the HNS planning in cooperation with the Operational Commander. An HNS SUPLAN will support developed CONPLANs, SDPs, OPLANs and other SUPLANs as appropriate, as well as be a stand-alone plan.

\section{Operation Orders (OPORDs)}

A commander issues an OPORD to his subordinate commanders for the purpose of effecting the co-ordinated planning and execution of an on-going operation. OPORDs for a given OPLAN will be issued once the authorization has been granted. 


\section{Other Planning Factors}

In the course of development of planning procedures and operation plans, other planning factors may also have implications, such as:

- Doctrine,

- Concepts,

- Agreements and

- National Legislation

\section{Review, Revision and Cancellation}

The periodic review, revision, and/or cancellation of standing operation plans are necessary to ensure their long-term credibility and utility. Revisions and/or cancellations of standing operation plans will occur when circumstances under which these plans were developed have changed.

The Serbian Armed Forces commanders are required to:

1. Maintain a current status of their plans as well as those of their immediate subordinate commanders.

2. Develop procedures applicable to their subordinate forces to facilitate the conduct of comprehensive and partial reviews of all standing plans.

3. Determine follow-up actions to be taken as a result of such reviews, including changes to the command's own plan or operations planning documents or recommended changes to superior commanders' planning and other basic documents.

\section{Review} ability.

Review must occur in all functional areas to evaluate and confirm feasibility and vi-

Plans must be reviewed when:

1. There is a significant alteration to the situation.

2. A period of 24 months has elapsed since initial approval or the last comprehensive review.

3. The review will dictate the degree of revision required or cancellation of plans as appropriate.

\section{Revision}

Revisions are made to the operation plans when changes are required, but the fundamental elements of operational design remain sound.

Requirement for formal re-approval will depend on the degree of changes made:

1. Purely editorial changes and other non-substantive amendments may be issued by the originator when appropriate and without approval or justification.

2. Major changes will require approval in accordance with the procedures detailed for newly developed plans. 


\section{Cancellation}

The cancellation of an operation plan is necessary when the circumstances under which the plan was developed have changed to the degree that the plan is no longer viable or relevant. The cancellation of a plan or other operations planning document requires the authority of the original approving authority. The cancellation of a plan will cancel its SUPLANs, associated subordinate level plans, and OPORDs, unless ordered otherwise.

\section{Roles and responsibilities}

The design of the OPP provides the maximum freedom for planning staffs to develop ideas and concepts in the preparation of operation plans. The early steps of OPP are critical for orienting the planning process. Clear direction from the strategic level is essential before planning and orienting of its direction can commence.

Operational planning may be conducted simultaneously at a number of command levels, depending on the nature of the operation and the scope of the plan being developed. The roles and responsibilities of the various levels of authority in the initiation, development, approval, and execution of operational plans fall on various authorities.

\section{Planning Authorities/Responsibilities}

Within the national operational planning system there is a clear division of responsibilities for initiation, development, approval, execution, and cancellation of operational plans. These responsibilities are divided amongst the Minister of Defence, CHOD, Operational Commander, and subordinate Commanders within the military command structure.

\section{Responsibilities for deliberate (advance) planning}

Specifically, the division of responsibilities for deliberate (advance) planning is described as follows:

\section{a. Political level}

The Government approves the National Military Strategy (should be developed) that provides broad political guidance for deliberate (advance) planning. The Minister of Defence is the senior political authority within the defence establishment and as such he is responsible for the initiation and review of all deliberate (advance) operational plans. In the course of the political-military estimate (PME) process, the Minister will select one or more military actions and/or a category of operation plan(s) from those recommended by CHOD for his consideration. Should the Minister decide on a requirement for the development of an operation plan, he would issue an Initiating Directive (political guidance) to initiate the appropriate CONPLAN, SDP or FP. The Minister is also responsible for the review, revision, or cancellation of plans developed under his Initiating Directive, with approving authority delegated to the CHOD.

\section{b. $C H O D$}

The CHOD is responsible during the PME process for assisting the Minister of Defence in his deliberations concerning the initiation of CONPLAN or SDP development. Should the Minister decide on a requirement for military planning, the CHOD is responsi- 
ble for translating political guidance into strategic military direction for the Operational Commander and development of a Military Estimate. The CHOD is responsible for approving CONOPS, developed by the $\mathrm{HQ}$ of the Serbian Armed Forces/Joint Operational Command $(\mathrm{JOC})$ in the course of deliberate planning. The CHOD is also responsible for approving a CONPLAN, FP or SDP that is developed by $\mathrm{JOC} / \mathrm{HQ}$ of the Serbian Armed Forces prior to its being forwarded to the Minister for review, as well as for revising and cancelling CONPLANs or SDPs. FPs prepared for operations in support of civil authorities must be coordinated with the appropriate agencies.

\section{c. Operational Commander}

The Operational Commander is responsible, when directed by the CHOD, for assisting in the development of the Military Estimate. When directed by the CHOD, the Operational Commander is responsible for the development of a CONOPS, and the associated CONPLAN, FP or SDP. Where appropriate, the Operational Commander is responsible for development of the necessary SUPLANs. When the strategic level plans are complete, they are forwarded to CHOD for approval. The Operational Commander is responsible for approving subordinate plans. The Operational Commander is also responsible for the coordination of force activation planning that is then conducted at the tactical level.

\section{d. Subordinate Military Commanders}

Subordinate military commanders are responsible, when so tasked by the appropriate Initiating Authority, for the development of subordinate-level CONOPs and associated plans and, where appropriate, the development of any necessary SUPLANs and/or OPORDs. Plans developed by commanders at this level will be submitted to the next higher level of command for approval.

\section{Responsibilities for crisis response planning}

Specifically, the division of responsibilities for crisis response planning is described as follows:

\section{a. Political Level}

The overall responsibility for Crisis Response actions resides with the Governmental Crisis Committee (or appropriate equivalent) and the Minister of Interior. To the extent in which Crisis Response activities concern the sphere of responsibility of the MOD, the Minister of Defence is the senior political authority. As such, he is responsible for the initiation and approval of all operational plans developed in response to an actual or developing crisis. In the course of the political-military estimate (PME) process, the Minister will select one or more military response options from those submitted by CHOD for his consideration. Should the Minister decide on a requirement for military action, he will issue an Initiating Directive (political guidance) to launch detailed operational planning. The Minister will review the CONOPS developed by HQ SAF/JOC and approved by the CHOD. The Minister reviews the OPLAN, developed by JOC/HQ SAF and approved by the CHOD, and submits to the Government a request for Force Activation and/or changes in the current status of readiness of the SAF. The Minister is also responsible for the review, revision, or cancellation of plans that are developed under his Initiating Directive, with approving authority delegated to the CHOD. 


\section{b. $C H O D$}

The $\mathrm{CHOD}$ is responsible during the PME process for assisting the Minister in his deliberations concerning the initiation of OPLAN development. Following this, the CHOD will submit potential military response options to the Minister for his consideration. Should the Minister decide on a requirement for military action, the CHOD is responsible for translating political guidance into strategic military direction for the HQ SAF and JOC. The CHOD is also responsible for approving a CONOPS developed by HQ SAF/JOC and an OPLAN developed by JOC/HQ SAF prior to its being forwarded to the Minister for review. He can also recommend revisions or cancellations of OPLANs to the Minister.

\section{c. Operational Commander}

The Operational Commander is responsible, when directed by the CHOD, for assisting in the further development or refinement of potential military response options during the PME process. Should the Minister decide on the requirement for military action, the Operational Commander is responsible for supporting HQ SAF in the development of CONOPS and then the development of an OPLAN with the support of HQ SAF. Where appropriate, the Operational Commander is responsible for the development of any necessary SUPLANs. When the OPLAN is complete, it is forwarded by the Operational Commander to CHOD for approval. The Operational Commander is responsible for approving subordinate plans as well as for the coordination of force activation planning that is conducted at tactical level.

\section{d. Subordinate Military Commanders}

Subordinate military commanders are responsible, when so tasked by the appropriate Initiating Authority, for the development of subordinate-level CONOPs and associated plans, and, where appropriate, the development of any necessary SUPLANs and/or OPORDs. Plans developed by commanders at this level will be submitted to the next higher level of command for approval.

\section{Conclusion}

Operational planning should be coherent with other non-military and potentially multinational and non-governmental initiatives intended to stabilize and create a selfsustaining secure environment. A Serbian Defence Organization response must therefore be integrated into a wider overall framework or a comprehensive approach.

This research paper does not elaborate on the preparation of commanders, staffs or forces for operations. However, the importance of this preparation should not be underestimated as it impacts on force structures, training, doctrine, concepts and other mission essential factors.

\section{References}

[1] Andreski, Stanislav. Military organization and society, Berkeley: University of California Press, 1968.

[2] Art, Robert J., Vincent Davis, and Samuel P. Huntington. Reorganizing America's Defence: Leadership in War and Peace. Washington, DC: Pergamon-Brassey's, 1985. 
[3] Australia. Department of Defence, Future Directions for the Management of Australia's Defence, Report of the Defence Efficiency Review, DPUBS: 26975/97, Canberra, 10 March 1997.

[4] Australia. Department of Defence, Addendum to the Report of the Defence Efficiency Review, Secretariat Papers, DPUBS: 27118/97, Canberra, 1997.

[5] Barrett, Archie D. Reappraising Defence Organization: an analysis based on the defence organization study of1977-1980, Washington, DC: National Defence University Press, 1983.

[6] Bland, Douglas. Canada's National Defence - Volume 2: Defence Organisation, Kingston, Ontario: School of Policy Studies, Queen's University, 1998.

[7] Bland, Douglas. Chiefs of Defence: Government and the Unified Command of the Canadian Forces, Toronto, Canadian Institute of Strategic Studies, 1995.

[8] Bruneau, Thomas C. and Richard B. Goetze. "Ministries of Defence and Democratic Control", in Bruneau, Thomas C. and Scott D. Tollefson, eds., Who Guards the Guardians and How: Democratic Civil-Military Relations, Austin: University of Texas Press, 2006, pp. 71-98.

[9] Bruneau, Thomas C. and Florina Cristiana Matei. "Towards a New Conceptualization of Democratization and Civil-Military Relations", Democratization, VoLI5, No.5, December 2008, pp. 909-929.

[10] v. Clausewitz, Carl. On War, ed. and translated by Michael Howard and Peter Paret, Princeton: Princeton University Press, 1984.

[11] Clemmesen, Michael H. "Integration of new alliance members: The intellectual-cultural dimension," Defence Analysis (Special issue: NATO at Fifty, ed. by Andrew Dorman and ThomasDurell Young), Vol. 15, No.3, December 1999, pp. 261-272.

[12] Craig, Gordon A. The Politics of the Prussian Army, 1640-1945. New York: Oxford University Press, 1955.

[13] Edmunds, Martin. ed. Central organizations ofdefence. Boulder, CO: Westview Press, 1985.

[14] Evans, Michael. The Tyranny of Dissonance: Australia's strategic culture and way of war, 1901-2005, Study Paper 306, Canberra: land Warfare Studies Centre, February 2005.

[15] Epstein, Rachel A. In pursuit of liberalism: International institutions in postcommunist Europe, Baltimore: The Johns Hopkins University Press, 2008 (chapter 5).

[16] Gearson, John, et al. "The HERO Review: Harnessing Efficiencies, Rethinking Outcomes: The Future of the Defence Estate", MS3370, London, Morgan Sindall, 2011.

[17] Goldman, Emily and Leslie C. Eliason, eds. The Diffusion of Military Technology and Ideas, Stanford: Stanford University Press, 2003.

[18] Gosselin, Daniel. "The Canadian Forces in Transition: Hellyer's Ghost", Canadian Military Journal Vol. 9, No 2, 2009; 'Part Two' Vol 9, No 3, 2009, http://www.journal.forces.gc.ca/ Grattan, Robert F. Strategic Review: The process of strategy formulation in complex organisations, Farnham, Surrey: Gower Publishing Limited, 2011.

[19] Hartley, Keith and Todd Sandler, eds. Handbook ofdefence economics, Volume 1, New York: Elsevier, 1995.

[20] Hellyer, Paul. Damn the torpedoes: my fight to unify Canada's armed forces, Toronto, Ont.: M\&S, 1990.

[21] Hicks, Kathleen H. Invigorating Defence Governance: A Beyond Goldwater-Nichols Phase 4 Report, Washington, DC: Center for Strategic and International Studies, March 2008.

[22] Hintze, Otto. "Military organization and state organization", in The Historical Essays of Otto Hintze, ed. by Felix Gilbert. New York: Oxford University Press, 1975, 178-215.

[23] Howard, Michael. The Franco-Prussian War: The German invasion of France. New York: Methuen, 1979.

[24] Howard, Michael. Lessons of History. New Haven: Yale University Press, 1991. 
[25] Locher, James R. III. Victory on the Potomac: the Goldwater-Nichols Act unifies the Pentagon, College Station: Texas A \& M University Press, 2002.

[26] Lovelace, Douglas C. and Thomas-Durell Young. "Defining USACOM's Role in the Power Projection Strategy", Carlisle Barracks, PA: Strategic Studies Institute, 1998.

[27] McCarthy, Anna, et al. "Joint Warfare Capability Assessment: Final Report: Australian Joint Essential Tasks", Volume 1, DSTO-CR-0293, Edinburgh, SA: Defence Scientific and Technology Organisation, 2003.

[28] Paret, Peter. "Napoleon and the Revolution in War," in Makers of Modern Strategy: From Machiavelli to the Nuclear Age, ed. by Peter Paret, Princeton: Princeton University Press, 1986, pp. 123-142.

[29] Ralston, David B. Importing the European Army: The introduction of European military techniques and institutions into the extra-European world, 1600-1941, Chicago: The University of Chicago Press, 1990.

[30] De Spiegeleire, Stephan, et at. Closing the Loop: Towards Strategic Defence Management, The Hague: The Hague Centre for Defence Studies, 2009.

[31] Shemella, Paul. "The Spectrum of Roles and Missions of the Armed Forces," in Thomas C. Bruneau, and Scott D. Tollefson, eds., Who Guards the Guardians and How: Democratic CivilMilitary Relations, Austin: University of Texas Press, 2006, pp. 122-142.

[32] Simpkin, Richard E. Race of the Swift: Thoughts on Twenty-First Century Warfare, London: Brassey's, 1985.

[33] Strachan, Hew. The Politics of the British Army, Oxford: Clarendon Press, 1997.

[34] Supreme Headquarters Allied Power Europe, Belgium, "Guidelines on Operational Planning (GOP)," J5PLANSI7630-058/05 - 105603, Final Revision 1, June 2005, NATO RESTRICTED, Releasable to PfP and EU.

[35] U.S. Chairman of the Joint Chiefs of Staff Instruction, Chairman of the Joint Chiefs of Staff, Combatant Commanders, and Joint Staff Participation in the Planning, Programming, Budgeting, and Execution System, CJCSI 8501.01A, Washington, DC, 03 December 2004.

[36] U.S. Chairman of the Joint Chiefs of Staff Instruction, Joint Strategic Planning System, CJCSI 3100.01B, Washington, DC, 12 December 2008.

[37] U.S. Department of Defence, Transformation Planning Guidance, Washington, D.C., Department of Defence, April 2003.

[38] United Kingdom. Strategic Defence Review, Presented to Parliament by the Secretary of State for Defence by Command of Her Majesty, July 1998 http://www.mod.ukINR/ rdonlyres/65F3D7AC-4340-4119-93A2-20825848E50E/0/sdr1998_complete.pdf

[39] Wilkinson, Spenser. The Brain of an Army: A popular account of the German General Staff, Westminster: Archibald Constable, 1895.

[40] Young, Thomas-Durell. "Post-unification German military organisation: the struggle to create national command structures", in German at fifty-five: Berlin ist nicht Bonn? ed. by James Sperling, New York: Manchester University Press, 2004, pp. 325-347.

[41] Young, Thomas-Durell. "The Revolution in Military Affairs and Coalition Operations: Problem Areas and Solutions", Security and Defence Analysis, Volume 19, No.2, June 2003, pp. 111-130. 